\title{
Detection of antibodies against phenolic glycolipid-1 (PGL-1), 35-kDa and 30-40-kDa components of Mycobacterium leprae in the cerebrospinal fluid of leprosy patients
}

\author{
SHRIPAD A. PATIL*, KIRAN KATOCH, G. RAMU $\dagger$ and U. SENGUPTA \\ Immunology Laboratory and Clinical Section (Unit-1), Central Jalma Institute for Leprosy, Taj Ganj, \\ Agra-282001, India
}

\begin{abstract}
Summary. The involvement of the central nervous system (CNS) in lepromatous leprosy (LL) patients was investigated; 33 patients were examined clinically in detail and upper motor neuron involvement was observed in eight and lower motor neuron in three of these patients. Anti-Mycobacterium leprae antibodies could be detected in the CSF by PGL-1 enzyme-linked immunosorbent assay (ELISA) and monoclonal antibody (MAb) based competitive assays against defined epitopes on the $35-\mathrm{kDa}$ protein and $30-40-\mathrm{kDa}$ polysaccharide (lipoarabinomannan) antigens with MAbs MLO4 and ML34, respectively. Antibodies against PGL-1 and $35-\mathrm{kDa}$ protein were observed in more subjects than antibodies against the $30-40-\mathrm{kDa}$ antigen. Some correlation was observed between the upper motor neuron signs and antibody positivity for $35-\mathrm{kDa}$ and PGL-1 antigens in the CSF of these patients.
\end{abstract}

\section{Introduction}

Leprosy is a chronic infectious disease caused by the obligate intracellular mycobacterium, Mycobacterium leprae. This hitherto uncultivated mycobacterium has a special affinity for nerve cells. ${ }^{1}$ Although peripheral nerves are primarily infected, ${ }^{2}$ only a few studies have examined the central nervous system (CNS) in leprosy. ${ }^{3}$ Blood and tissues have been shown to contain a very high load of the pathogen. ${ }^{4}$ High levels of antibodies have also been detected in the serum of leprosy patients by various immunological techniques. ${ }^{5}$ In normal conditions, passing of such antibodies from blood into the cerebrospinal fluid (CSF) is generally prevented by the blood-brain barrier (BBB) ${ }^{6}$ However, immunoglobulins and antibodies are detected in the CSF of patients with certain bacterial infections (tuberculous meningitis-TBM-,? syphilis ${ }^{8}$ ) and viral infections (AIDS, ${ }^{9}$ mumps $^{10}$ ). The presence of $M$. leprae antigens was demonstrated recently in the CSF of lepromatous leprosy (LL) patients. ${ }^{11}$ In another study, ${ }^{3}$ anti-M. leprae antibodies

Received 12 Oct. 1993; revised version received 19 Dec. 1994; accepted 2 Feb. 1995.

*Present address and address for correspondence: Department of Microbiology, National Institute of Mental Health and Neurosciences, Bangalore 560029, India.

†Present address: 1075 3E Pioneer Complex, Avinasi Road, Coimbatore 641018, India. to whole $M$. leprae were detected in $c .55 \%$ of LL cases. However, the antigenic specificities of these antibodies that might be relevant in understanding the possible CNS involvement in leprosy were not established. In the present study, the CSF samples from leprosy patients were analysed for the presence of antibodies against PGL-1 and against $M$. lepraespecific and mycobacterial common antigenic epitopes by monoclonal antibody (MAb)-based competitive assays.

\section{Materials and methods}

\section{Subjects}

Thirty-four patients who were active cases of LL admitted to the Central JALMA Institute of Leprosy, Agra, were selected for the study. Clinical classification of the disease was done by the criteria of Ridley and Jopling. ${ }^{12}$ All the cases were male and were aged 25-55 years. All were undergoing treatment for leprosy and had had the disease for 2-14 years with a mean duration of 4.7 years. The higher mental functions of all these patients were within normal limits. After a detailed clinical examination of the patients, CSF samples were obtained aseptically by lumbar puncture. Blood samples for serum were collected from the antecubital vein of these patients. CSF samples from 14 subjects with TBM were provided by $\mathrm{Dr} A$. 
Table I. Major clinical findings and antibody data of individual patients

\begin{tabular}{|c|c|c|c|c|c|c|c|c|c|}
\hline \multirow{3}{*}{ Patient } & \multicolumn{4}{|c|}{ Percentage binding values* } & \multicolumn{4}{|c|}{$\begin{array}{c}\text { Optical density (OD) } \\
\text { values of } \\
\text { PGL-antibody }\end{array}$} & \multirow{3}{*}{$\begin{array}{l}\text { Salient } \\
\text { clinical } \\
\text { features }\end{array}$} \\
\hline & \multicolumn{2}{|c|}{ MLO4 } & \multicolumn{2}{|c|}{ ML34 } & \multicolumn{2}{|c|}{ IgG } & \multicolumn{2}{|c|}{$\operatorname{IgM}$} & \\
\hline & Serum & CSF & Serum & $\mathrm{CSF}$ & Serum & CSF & Serum & CSF & \\
\hline LP & 20 & 81 & 71 & 90 & $0 \cdot 18$ & 0.13 & $0 \cdot 27$ & 0.12 & NAD \\
\hline $\mathrm{S}$ & 11 & 53 & 8 & 83 & $0 \cdot 16$ & $0 \cdot 17$ & 0.28 & 0.02 & Ext planter \\
\hline $\mathrm{RD}$ & 6 & 45 & 5 & 87 & 0.60 & 0.291 & 0.63 & 0.14 & $\uparrow$ reflexes \\
\hline KK & 8 & 60 & 11 & 90 & 0.33 & $0 \cdot 38$ & $0 \cdot 24$ & 0.02 & NAD \\
\hline DM & 20 & 66 & 12 & 90 & $0 \cdot 39$ & 0.6 & $0 \cdot 56$ & 0.072 & NAD \\
\hline$K R$ & 6 & 57 & 7 & 67 & 0.13 & $0 \cdot 14$ & $0 \cdot 35$ & 0.02 & NAD \\
\hline $\mathrm{AK}$ & 9 & 75 & 2 & 68 & 0.36 & 0.38 & 0.13 & 0.02 & NAD \\
\hline A & 2 & 24 & 2 & 67 & 0.46 & $0 \cdot 22$ & $0 \cdot 17$ & $0 \cdot 15$ & $\uparrow$ reflexes \\
\hline $\mathrm{R}$ & 9 & 82 & 8 & 90 & $0 \cdot 23$ & $0 \cdot 26$ & $0 \cdot 33$ & 0.02 & NAD \\
\hline $\mathrm{KR}^{2}$ & 5 & 66 & 22 & 97 & 0.47 & 0.46 & 0.24 & 0.02 & NAD \\
\hline $\mathrm{MA}$ & 7 & 50 & 2 & 85 & 0.36 & 0.35 & 0.42 & 0.03 & NAD \\
\hline RL & 5 & 47 & 1 & 83 & 0.35 & 0.15 & 0.31 & $0 \cdot 01$ & $\downarrow$ reflexes \\
\hline SS & 13 & 68 & 60 & 97 & 0.28 & 0.30 & 0.60 & 0.01 & NAD \\
\hline KP & 6 & 33 & 37 & 90 & 0.20 & 0.79 & $0 \cdot 16$ & 0.02 & NAD \\
\hline B & 6 & 31 & 1 & 68 & 0.58 & $0 \cdot 16$ & $1 \cdot 16$ & $0 \cdot 10$ & NAD \\
\hline SHS & 25 & 58 & 2 & 83 & $0 \cdot 41$ & $0 \cdot 14$ & $0 \cdot 29$ & $0 \cdot 88$ & $\begin{array}{l}\text { I, VIII cranial } \\
\text { nerve involved }\end{array}$ \\
\hline PM & 16 & 80 & 4 & 90 & 0.29 & 0.40 & $0 \cdot 23$ & $0 \cdot 01$ & NAD \\
\hline TR & 19 & 66 & 23 & 87 & $0 \cdot 36$ & 0.19 & $0 \cdot 61$ & 0.02 & NAD \\
\hline LR & 13 & 47 & 38 & 67 & 0.75 & $0 \cdot 18$ & 0.87 & $0 \cdot 02$ & $\downarrow$ reflexes \\
\hline $\mathrm{LP}^{2}$ & 15 & 41 & 15 & 83 & 0.22 & 0.09 & 0.29 & 0.04 & NAD \\
\hline $\mathrm{SQ}$ & 13 & 74 & 46 & 84 & $0 \cdot 30$ & $0 \cdot 30$ & 0.49 & 0.04 & NAD \\
\hline$N$ & 8 & 49 & 32 & 87 & $0 \cdot 17$ & 0.15 & $0 \cdot 22$ & 0.04 & NAD \\
\hline $\mathrm{S}$ & 19 & 75 & 15 & 85 & $0 \cdot 17$ & $0 \cdot 32$ & $0 \cdot 22$ & 0.03 & NAD \\
\hline $\mathrm{P}$ & 23 & 77 & 70 & 97 & 0.44 & $0 \cdot 15$ & $0 \cdot 29$ & 0.04 & Not done \\
\hline$M$ & 17 & 69 & 8 & 48 & $0 \cdot 23$ & 0.09 & 0.34 & 0.04 & NAD \\
\hline $\mathrm{BO}$ & 8 & 75 & 7 & 83 & 0.49 & 0.47 & 0.49 & 0.15 & NAD \\
\hline IA & 3 & 59 & 65 & 87 & $0 \cdot 11$ & 0.15 & $0 \cdot 10$ & 0.02 & $\uparrow$ reflexes \\
\hline $\mathrm{DP}$ & 2 & 50 & 8 & 70 & 0.44 & 0.08 & 0.29 & 0.03 & NAD \\
\hline $\mathrm{BA}$ & 9 & 30 & 8 & 38 & 0.49 & 0.08 & 1.80 & 0.02 & + reflexes \\
\hline AR & 6 & 60 & 11 & 97 & 0.47 & 0.39 & 0.58 & 0.09 & $\uparrow$ reflexes \\
\hline $\mathrm{MU}$ & 12 & 50 & 1 & 71 & $0 \cdot 34$ & $0 \cdot 28$ & 0.42 & 0.03 & NAD \\
\hline $\mathrm{AS}$ & 7 & 42 & 23 & 86 & 0.66 & $0 \cdot 11$ & 0.72 & 0.01 & reflexes \\
\hline KKA & 4 & 9 & 11 & 89 & 0.75 & 0.98 & 0.88 & $0 \cdot 10$ & $\uparrow$ reflexes \\
\hline $\mathrm{RC}$ & 9 & 32 & 17 & 47 & 0.46 & 0.34 & 0.17 & 0.03 & NAD \\
\hline
\end{tabular}

*Inhibition dilution $50=50 \%$ binding and below; this represents a positive resuit for MLO4 and ML34 both in serum and CSF.

$\nmid$ PGL- 1 IgG and IgM cut-off for serum is 0.20 ; for CSF cut-off limit for IgG is 0.32 and for IgM it is 0.07 , which are calculated on the basis of mean $+2 \mathrm{SD}$ of OD values of control CSF samples.

$\ddagger$ Exaggerated deep reflexes with clonus.

$\uparrow$ Reflexes, exaggerated deep reflexes $; \downarrow$ reflexes, hyporeflexia.

Chandramukhi of the National Institute of Mental Health and Neurosciences, Bangalore. CSF samples from 10 subjects with septic meningitis other than TBM were provided by Dr B. B. Maheswari of Sarojini Naidu Medical College, Agra; these served as controls in the study. All the samples were stored at $-70^{\circ} \mathrm{C}$.

\section{M. leprae antigen}

PGL-1 and cell-free extract of armadillo-derived $M$. leprae were obtained from $\mathrm{Dr} \mathrm{R}$. J.W. Rees, IMMLEP (WHO) Bank, National Institute for Medical Research, Mill Hill, London.

\section{$M A b s$}

The MAbs MLO4 and ML34, which bind to epitopes on $35-\mathrm{kDa}$ protein and $30-40-\mathrm{kDa}$ poly- saccharide components of $M$. leprae, respectively, ${ }^{13}$ were obtained from Dr J. Ivanyi, Hammersmith Hospital, London. These MAbs were labelled with ${ }^{125} \mathrm{I}$ (Bhabha Atomic Research Centre, Bombay, India) by the iodogen method. ${ }^{14}$

\section{Antibody competition test $(A C T)$}

Antibody responses were detected against epitopes on $35-\mathrm{kDa}$ protein and $30-40-\mathrm{kDa}$ polysaccharide components of $M$. leprae with ${ }^{125}$ I-labelled MAbs MLO4 and ML34 by ACT. ${ }^{15,16}$ In this method, binding of the labelled MAb to a defined antigenic epitope is inhibited by the antibody in the test sample. Serum samples were used at a dilution of 1 in 5 , whereas CSF samples were used neat to detect antibodies to $35-\mathrm{kDa}$ and $30-40-\mathrm{kDa}$ antigens. Samples showing $>50 \%$ inhibition of binding of ${ }^{125}$ I-labelled MAbs were considered positive. ${ }^{15,16}$ 


\section{PGL-1 ELISA}

Antibodies against PGL-1 were detected by indirect ELISA with peroxidase-conjugated anti-human IgG and IgM with O-phenylene diamine as substrate..$^{17,18}$ The CSF samples were used neat, whereas serum samples were used at a dilution of 1 in 300. Cut-off points for serum samples and for CSF samples were determined on the basis of mean of OD of controls +2 standard deviations.

\section{Results}

\section{Clinical findings}

Thirty-three patients were examined clinically in detail for CNS involvement. The higher mental functions were normal in all the patients and there was no inco-ordination of movement in any of them. The first and the eighth cranial nerves were involved in one patient. One patient had an extensor plantar response on one foot. In seven patients, the deep tendon reflexes at the knee and ankle were exaggerated, with mild clonus in two. In two patients there was a diminished response of the knee and ankle reflexes. None of these patients was a habitual alcoholic and none of them was suffering from generalised deficiency diseases. In the other patients, CNS function was within normal limits. The details of the CSF examination was given in table I.

\section{Antibodies against 35-kDa and 30-40-kDa components of $M$. leprae}

Fifteen $(44 \%)$ of the 34 subjects with leprosy showed antibody positivity in the CSF against the 35-kDa component of $M$. leprae (fig. 1). Antibodies against the 30-40-kDa component were detected in the CSF of three $(9 \%)$ of 34 patients. When CSF antibody levels were compared with the corresponding serum levels, all the sera had higher levels of antibodies (table I). Two (14\%) of 14 CSF samples from TBM cases were positive for both antibodies. None of the septic

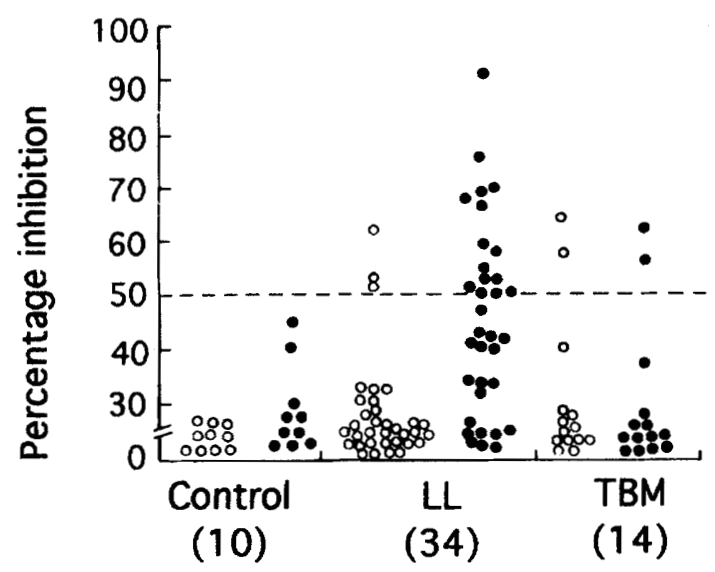

Fig. 1. Antibody levels detected by competitive assay with ML34 (O) and MLO4 (O) in CSF of controls, LL and TBM patients;---, cut-off point. meningitis samples was positive for either anti-35-kDa or anti-30-40-kDa antibodies.

\section{Anti-PGL-1 antibodies}

Twelve $(35 \%)$ of $34 \mathrm{CSF}$ samples from leprosy patients were positive for IgG antibodies against PGL1 at a cut-off point of $0.32 \mathrm{OD}$ (fig. $2 \mathrm{a}$ ), whereas nine $(26 \%)$ of 34 were positive for IgM at a cut-off point of 0.07 OD (fig. 2b). None of the CSF samples from the controls was positive for either IgG or IgM. However CSF samples from six (42\%) and eight $(57 \%)$ of 14 TBM cases were positive for IgG and IgM PGL-1 antibodies, respectively. The majority of serum samples from LL patients $(65 \%$ for IgG and $100 \%$ for IgM) had higher levels of antibodies than the corresponding CSF samples. While 22 serum samples were positive for IgG and all samples were positive for IgM, only two CSF samples were positive for IgG and 10 for IgM (table II).

\section{Discussion}

In experimental animals $M$. leprae has been shown to cross the $\mathrm{BBB}^{19}$ and the presence of $M$. leprae antigens in the CSF of leprosy patients has been reported previously. ${ }^{11}$ In the present study, antibody levels in serum and CSF against three well characterised $M$. leprae antigens were studied.

Eleven patients had clinical signs and symptoms of involvement of the CNS. Of these, one patient had involvement of the first and eighth cranial nerves and two patients had diminished deep tendon reflexes. These could be explained by the involvement of end organs or lower motor neurones, or both. Eight patients had upper motor neurone involvement, of whom one patient had extensor plantar response on the left side and seven others had exaggerated deep tendon reflexes of the knee and ankle joints. In two of these patients, there was also a mild clonus of the ankle joint. None of these patients had inco-ordination of movement or any other signs of extrapyramidal involvement (table I). If $50 \%$ binding for MLO4 is considered positive then 15 patients showed antibody positivity against the 35-kDa component of $M$. leprae. However, if the three patients who had exact $50 \%$ antibody binding are not considered as antibody positive, and only those patients are included who had $>50 \%$ binding, then 12 patients were positive for MLO4, of whom five had upper motor neurone signs and two had lower motor neurone signs. When the Pearson $\chi^{2}$ is applied between MLO4 positivity about $50 \%$ binding and upper motor neurone signs, 0.019 is obtained, which after Yate's correction comes to 0.058 which is slightly significant (table III). It is possible that if the study had been conducted in more patients the probability of having a better statistical correlation would have been increased.

In the CSF samples, IgM PGL-1 antibody was 
a

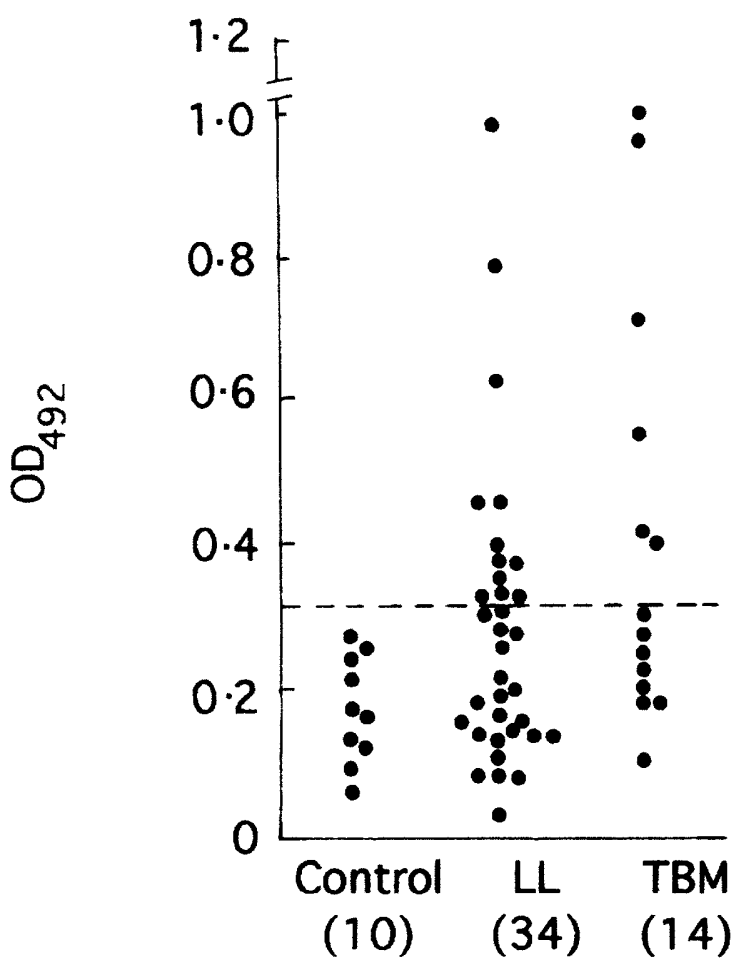

b

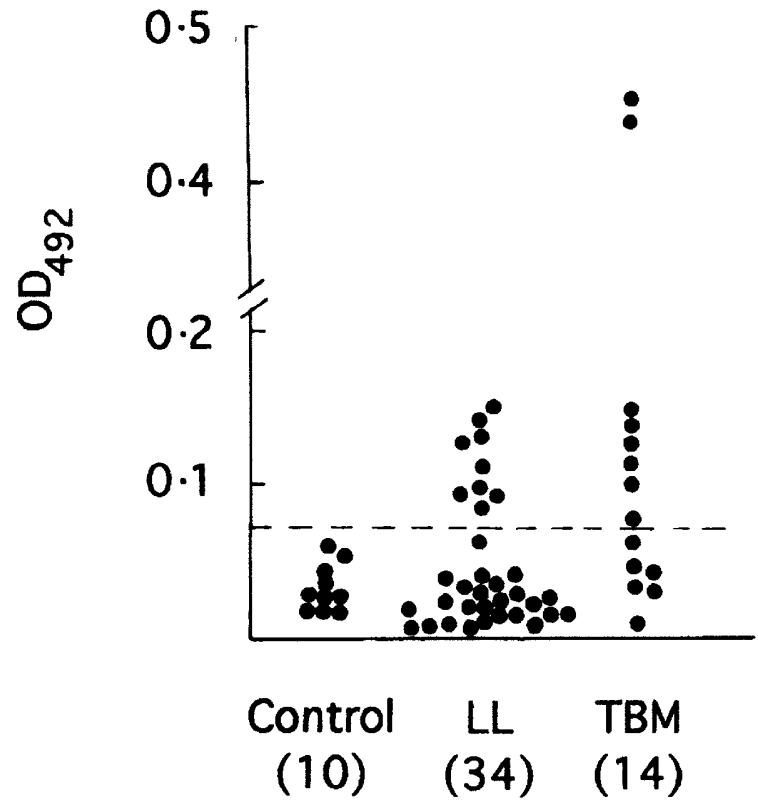

Fig. 2. Antibody levels to PGL-1 of $M$. leprae in CSF of LL patients and controls as detected by indirect ELISA: a anti-PGL-1 IgG; b, antiPGL-1 IGM ; --, cut-off point.

Table II. Comparative data on antibody positivity of CSF samples from 34 patients for $M$. leprae antigens

\begin{tabular}{lcccc}
$\begin{array}{l}\text { Antibody } \\
\text { test } \\
\text { result }\end{array}$ & Anti-35 kDa & Anti-ML-34 & PGL-IgG & PGL-IgM \\
\hline $\begin{array}{l}\text { Positive } \\
\text { Negative }\end{array}$ & 15 & 3 & 12 & 9 \\
$\begin{array}{l}\text { Percentage } \\
\text { positive }\end{array}$ & 44 & 31 & 22 & 25 \\
& & 9 & 35 & 26 \\
\hline
\end{tabular}

Table 1II. Statistical correlation between upper motor neurone signs and levels of anti-35-kDa and PGL-1 IgM

\begin{tabular}{lcclccc}
\hline $\begin{array}{l}\text { Upper } \\
\text { motor } \\
\text { neurone } \\
\text { status }\end{array}$ & \multicolumn{2}{c}{$\begin{array}{c}35-\mathrm{kDa} \text { antibody* } \\
(\mathrm{n}=30)_{+}^{\ddagger}\end{array}$} & & & \multicolumn{2}{c}{$\begin{array}{c}\text { PGL-1 IgM } \dagger \\
(\mathrm{n}=33) \S\end{array}$} \\
\cline { 2 - 3 } \cline { 5 - 6 } \cline { 5 - 6 } & positive & negative & & positive & negative \\
\hline $\begin{array}{l}\text { Positive } \\
\text { Negative }\end{array}$ & 5 & 3 & & 5 & 6 \\
\hline
\end{tabular}

*Pearson $\chi^{2}$ value 0.019, after Yates's correction 0.058.

+Pearson $\chi^{2}$ value 0.04, after Yates's correction 0.11.

†Three patients with exactly $50 \%$ binding were not included in either group.

§Detailed CNS examination of one IgM positive case was not possible and was excluded from the analysis.

Two of these patients had diminished deep reflexes.

present in nine patients and IgG PGL-1 antibody was in 12 patients. In the majority of the serum samples, levels of antibodies were lower than those in earlier reports. ${ }^{20}$ This could be due to long continuous treatment of the patients in the current study, which is known to bring down the level of PGL-1 antibodies. ${ }^{20,21}$ Again, a slight variation was found with the Pearson $\chi^{2}$ test for the values of IgM in CSF and upper motor neurone signs. The Pearson $\chi^{2}$ test value was 0.044 and after Yates's correction it was $0 \cdot 11$ (table III). The present study shows that of the antibodies tested, MLO4 and IgM PGL-1 had some statistical correlation with the presence of upper motor neurone signs.

The finding of anti-35-kDa and IgG/IgM PGL-1 positivity in TBM cases might be due to the presence of concomitant infection with both tuberculosis and leprosy in these cases. A high level of IgM PGL-1 activity appears to confirm that some of these patients were also suffering from leprosy. As these patients were not kept under surveillance, no firm conclusion can be made.

In the present study, the levels of antibodies in CSF do not seem to be due to a breach in the BBB, because in that case the antibody levels in both CSF and serum would be similar. Moreover, in eight of the LL cases the IgG PGL-1 response was higher in CSF than the corresponding level in serum. These findings suggest that the antibodies in CSF are due to local production of antibody by the lymphocytes in CSF. However, further confirmation by culturing the CSF cells in vitro and demonstrating the production of such antibodies in situ, as in other diseases, ${ }^{7,22}$ is required.

Although our earlier study established the presence 
of antibodies against whole $M$. leprae in the CSF of $55 \%$ of LL cases by the FLA-ABS test, ${ }^{3}$ the present study establishes the presence of antibodies against two $M$. leprae-specific antigens and a common mycobacterial polysaccharide antigen in the CSF of LL patients. These findings also point to an association between the presence of these antibodies and upper

\section{References}

1. Mukherjee R, Antia NH. Adherence of M. leprae to Schwann cells in vitro: a specific phenomenon. IRCS Med Sci 1985; 13: $853-854$.

2. Boddingius J. The occurrence of Mycobacterium leprae within axons of peripheral nerves. Acta Neuropathol 1974; 27 : $257-270$.

3. Katoch K, Ramu G, Sengupta U, Bharadwaj VP. Central nervous system involvement in leprosy. Indian J Lepr 1984; 56: $813-818$.

4. Drutz DJ, Chen TSN, Lu W-H. The continuous bacteremia of lepromatous leprosy. $N$ Engl J Med 1972; 287: 159-164.

5. Anonymous. Serological tests for leprosy. Lancet 1986; 1: 533-535.

6. Griffin DE, Giffels J. Study of protein characteristics that influence entry into the cerebrospinal fluid of normal mice and mice with encephalitis. J Clin Invest $1982 ; 70: 289-295$.

7. Daniel TM, Debanne SM. The serodiagnosis of tuberculosis and other mycobacterial diseases by enzyme-linked immunosorbent assay. Am Rev Respir Dis 1987; 135 1137-1151.

8. Lee JB, Farshy CE, Hunter EF, Hambie EA, Wobig GH, Larsen SA. Detection of immunoglobulin $\mathbf{M}$ in cerebrospinal fluid from syphilis patients by enzyme-linked immunoabsorbent assay. $J$ Clin Microbiol 1986; 24: 736-740.

9. Goudsmit J, Paul DA, Lange, JMA et al. Expression of human immunodeficiency virus antigen (HIV-Ag) in serum and cerebrospinal fluid during acute and chronic infection. Lancet $1986 ; 2$ : 177-180.

10. Frydan A, Link H, Norrby E. Cerebrospinal fluid and serum immunoglobulins and antibody titers in mumps meningitis and aseptic meningitis of other etiology. Infect Immun 1978; 21 : 852-861.

11. Patil SA, Tyagi P, Katoch K, Sreevatsa, S, Sengupta, U. Antigens of Mycobacterium leprae in the cerebrospinal fluid of leprosy patients: detection by monoclonalantibody-based sandwich immunoradiometric assay and avidin/biotin based immunoblotting. Clin Exp Immunol $1991 ; 84: 515-521$.

12. Ridley DS, Jopling WH. Classification of leprosy according to immunity. A five-group system. Int $J$ Lepr 1966; 34: 253-273. motor neurone signs. Such an association should be investigated in a larger number of patients followed for a longer period.

We thank LEPRA, UK for the supply of some of the reagents, Sri A. S. Bhatia for statistical analysis, Sri Hari Om and Neeraj Dubey for photography and Sri Anil Kumar Chopra for secretarial help.

13. Ivanyi J, Sinha S, Aston R, Cussell D, Keen M, Sengupta U. Definition of species specific and cross-reactive antigenic determinants of Mycobacterium leprae using monoclonal antibodies. Clin Exp Imuunol 1983; 52: 528-536.

14. Fraker PJ, Speeck JC. Protein and cell membrane iodinations with a sparingly soluble chloramide, 1,3,4,6-tetrachloro3,6 a-diphenylglycoluril. Biochem Biophys Res Commun 1978; 80: 849-857.

15. Hewitt J, Coates ARM, Mitchison DA, Ivanyi J. The use of murine monoclonal antibodies without purification of antigen in the serodiagnosis of tuberculosis. $J$ Immunol Methods 1982; 55: 205-211.

16. Sinha S, Sengupta U, Ramu G, Ivanyi J. Serological survey of leprosy and control subjects by a monoclonal antibodybased immunoassay. Int J Lepr Other Mycobact Dis 1985; 53: $33-38$.

17. Cho S-N, Yanagihara DL, Hunter SW, Gelber RH, Brennan PJ. Serological specificity of phenolic glycolipid 1 from Mycobacterium leprae and use in serodiagnosis of leprosy. Infect Immun 1983; 41: 1077-1083.

18. Patil SA, Katoch K, Singh KP, Ramu G, Sengupta U. Antibodies to phenolic glycolipid-1 of Mycobacterium leprae in urine of leprosy patients. J Infect Dis 1990; 162: 281-283.

19. Vaidya MC, Palmer E, Weddell G, Rees RJW. A note on the presence of Mycobacterium leprae in the central nervous system of a mouse with lepromatous leprosy. $J$ Med Microbiol 1970; 3: 194-196.

20. Klaster PR, DeWit MYL, Fajardo TT et al. Evaluation of Mycobacterium leprae antigens in the monitoring of a dapsone-based chemotherapy of previously untreated lepromatous patients in Cebu, Philippines. Lepr Rev 1988; 60: 178-186.

21. Chaturvedi V, Sinha S, Girdhar BK, Sengupta U. On the value of sequential serology with a Mycobacterium leprae-specific antibody competition ELISA in monitoring leprosy chemotherapy. Int J Lepr Other Mycobact Dis 1991; 59: $32-40$.

22. Baig S, Olsson O, Olsson T, Lone A, Jeanssen S, Link H. Cells producing antibody to measles and herpes simplex virus in cerebrospinal fluid and blood of patients with multiple sclerosis and controls. Clin Exp Immunol 1989; 78: 390-395. 